\title{
Distributed Generation Application in the Rural Areas of West China
}

\author{
Yanfei Su, Chenxu Zhao, Long Xu, Xiaoyu Liu \\ The Bayannur power Bureau of Inner Mongolia Electric Power Group Co. Ltd., Hohhot, China \\ Email: bmzcx99@sina.com
}

Received February, 2013

\begin{abstract}
In this paper, at first the appearance background electricity grid in the rural areas of west China, and its meaning as well as the concept and structure of DG technologies are resented, and a DG technologies mode of development in the rural areas of west China is given. The development ideas and the future development direction of DG in are compared and summarized. At last, the significance of DG in future development of the rural areas of west China is prospected and some problems to be especially considered in the domestic research on DG technologies are put forward.
\end{abstract}

Keywords: Distributed Generation Technologies; Rural; West China; Application

\section{Introduction}

The rural power grid is an important part of the China State Grid, county and rural electricity consumption has accounted for $52 \%$ of the social consumption. Recent years, Western rural areas the rapid speed of development of electric power, the institutional structure of rural economy relative has undergone a major change, the electrical energy has become the development of the main driving force. State investment in rural grid began in 1998, Rural power grids implementation of the project lasted 14 years. Through the transformation of rural power grids, electricity has been greatly improved, but the city contrast, on safety, reliability remains a certain gap.[1] China's western rural has quality of solar resources, wind resources and biomass resources; the city is not these resources. So accelerate the construction to be strong based on the intelligent features of the new rural network. It is the goals and challenges faced by the agricultural and electrical work for the New Period, is also an inevitable requirement for the development of the rural power grid coordination at all levels.[2]

\section{The Feasibility of China's Western Rural Distributed Generation Application}

The large amount of solar energy resources in western China, western rural and remote areas without electricity accounted for $30 \%$ of the total, has a good solar conditions. Solar radiation total $6680-8400 \mathrm{mj} / \mathrm{m}^{2}$, equivalent to the amount of radiation $5.1-6.4 \mathrm{kw} / \mathrm{m}^{2}$ hours of annual sunshine time is $3200-3300 \mathrm{~h}$, the same amount of heat required standard coal-fired $225-285 \mathrm{~kg}$.
And have a good wind resources, the western perennial prevailing northwest wind at higher elevations, an average of about 1000 meters, the terrain is relatively flat with no obstacles, the temperature difference between day and night, making the air flow more strongly. Effective wind power density of 200 to 300 watts / square meter, wind speed greater than or equal to $3 \mathrm{~m} / \mathrm{s}$. The numbers of hours for more than 5000 hours throughout the year, throughout the year wind speed is greater than or equal to $6 \mathrm{~m} / \mathrm{s}$ the number of hours to 3000 hours or more.[3]

Through the comprehensive utilization of wind, solar and biomass, composition of the new energy structure micro-grid. Distributed Generation technology has long been in a foreign country, such as photovoltaic roof construction is common in Germany, the Netherlands and Japan and other countries. Directly powered by the Distributed Generation rural supplement to help the rural Eco-energy and comprehensive utilization of the space environment, is the inevitable choice for China's real sustainable social development and environmental protection.[4]

At present there are still large numbers of people without electricity in the remote areas of western China rural and pastoral areas. As the power lines power supply radius is too long, bad weather and external damage, and other reasons often cause power interruption, and recovery time compared to cities of the electricity very much worse, objectives for economic, safe and reliable electricity is quite a distance. In China, the use of Distributed Generation technology is still in its infancy, the National Development and Reform Commission 
response to increase investment and promote the use of the western Distributed Generation of China.

Distributed Generation technology in rural western China, the local distribution network in rural areas should be combined with the common run, two power grid to grid operation, but also the island run, these two models combined with the operating mode conducive to saving investment and reduce energy consumption and improve power system reliability and flexibility, is the world's many countries in energy, electricity experts recognized the future direction of development of electrical energy. Therefore, in the rural areas of micro-net technology is not only conducive to promoting the development and utilization of new energy and renewable energy, and help guide the electricity sector as well as policy-making departments to better develop the technology in the long run, China's western rural economic development also has important practical significance.

\section{The Definition of Distributed Generation}

The Distributed Generation system is a more independent and decentralized power network. Is any combination of renewable energy power generation equipment to the use of technology for the energy of the main power supply, solar photovoltaic, wind power, small hydro, biomass power generation, gas generation, battery group and so on? Then add the measurement and control devices, as a system, independent of the grid or the intermittent and grid connection, the formation of the joint operation of a utility grid and Distributed Generation power system.[5]

\section{Characteristic of Distributed Generation}

Flexible and free running mode, there are two modes of operation, and the network mode and islanding mode. And the network mode, the load can not only directly from the Power Supply Bureau, powered access, can also be obtained from the micro-grid, while the Distributed Generation access to energy at the same time, the transmission power to direct power supply. When the power supply capacity is insufficient or fails, the direct power supply and Distributed Generation are disconnected, operate independently, that is the island mode. Can it provide clean energy? Distributed Generation applications not only reduces the impact of distributed power supply for the safe operation of the distribution system, and help to achieve distributed power "plug and play", a reduction of environmental pollution, energy sustainable development, to provide users with a "green power", while the energy of the micro-network optimization is one important measure of management to maximize the use of renewable energy and clean energy, is the realization of China's energy saving target[6].

\section{Distributed Generation Operation Mode}

Distributed Generation operation mode is very flexible, with the joint operation of the direct supply grid or an independent can highlight its advantages. For example, the construction of the micro-network of high-density load areas (commercial, economic and technological development zones, schools, factories, demonstration area, etc.), the period of peak load and the distribution network in parallel operation, the use of micro-network power supply and distribution network as well as micro-network load power can alleviate the pressure of the supply of the distribution network, may also reduce the micro-power purchase costs; when Distributed Generation internal failure can be timely and direct supply grid is disconnected, without jeopardizing the safety of the grid; direct supply grid failure, the Distributed Generation load power supply from the grid independence of the region, and provide backup power for grid recovery; addition, according to grid electricity, the cost of micro-power generation, micro-network load structure and demand the preparation of operational plans can reduce Distributed Generation overall operating costs, this is very favorable to the economic operation of the combined power system.

\section{Distributed Generation Development Mode Western Rural of China}

According to local conditions, the village as a unit composed of different forms and different sizes of microgrid, their energy advantage, the use of the distributed power of rational science to form a micro-grid. For example, in sufficient wind energy resources in Inner Mongolia, Xinjiang and other regions should be a lot of development of small and medium-sized wind farm, the service to avoid the far farmers; sufficient sunlight in Qinghai, Tibet, Gansu, should play a decentralized supply of solar photovoltaic advantage of the promotion that allows the user to use photovoltaic power generation system. Combined with the different regions, wind energy, solar energy used in combination, to promote the integration of wind, light, storage system operation. Local conditions to the formation of various forms, the scale of the micro-network, so as to solve the problems of rural areas without electricity and the lack of electricity supply of the population, the progressive realization of the socialist new rural electrification. According to the investigation and analysis on the western rural electricity, I believe that should be adapted to local conditions to promote the use of the following two modes:

The first mode is the combination of "solar panels + wind power + battery pack" model, space is limited capacity, suitable for dispersion of single-family use, and 
the investment cost is small.

Solar panels system: a single block of solar panels power: $120 \mathrm{Wp}$, solar panels, photovoltaic power: 24 * $120 \mathrm{Wp}=2880 \mathrm{Wp}$. Taking into account the solar panels work angle of inclination of 25 degrees, bevel day average can be calculated daily generating capacity, four hours per day the amount of sunlight calculations. Experience the value of 0.806. Calculation of solar panels generating capacity: 9.4 degree.

Wind power generation system: fan power rating of 1 $\mathrm{KW}$, the average power of $0.6 \mathrm{KW}$; fans daily average generating capacity of 4 degrees.

The battery pack system: a set of battery capacity 12/200 AH with 2, 4 strings, and the combination of a total of: $400 \mathrm{AH}$.

Wind and solar system inverse transformer for $5 \mathrm{KW}$, the battery pack 400 the $\mathrm{AH}$, composed of single-user mode, per day generating about $4 \mathrm{kwh}$, to meet the power consumption of the rural and pastoral areas, residents of remote areas. Of course, the output of solar and wind every day fluctuate, so regardless of wind or solar energy must have a means of storing excess energy in order to store energy on a sunny day and wait for a rainy day use.

The second model is a combination of "solar panels + wind power + biogas generation” mode. Consisting mainly of methane generating units, there is enough capacity, suitable for the more concentrated the village, one-time investment is large.

Solar panels groups and modes of generation of wind power generation system with a single biogas generator sets to run a village community long-running $100 \mathrm{~kW}$ unit, for example, the continuous power of $80 \mathrm{~kW}$ is appropriate, unit annual generation capacity of $80 \mathrm{~kW} / \mathrm{h} \times$ $4000 \mathrm{~h}=320000 \mathrm{~kW}$ The can provide a small and medium-sized towns and villages in the production and living electricity.

Wind, solar photovoltaic, biomass power generation system to form a private network established in the township.

Direct power supply to have a professional connection point with the rural power grid. Energy ratio can be 5:3:2 and biomass power generation in rural areas accounted for $50 \%$ accounted for $30 \%$, solar photovoltaic, wind energy accounted for $20 \%$. It's major equipment for a solar photovoltaic power generation systems and netinverter system, a lead-acid battery energy storage system and bi-directional inverter, a methane gas power generation system, a fan power generation system. The application of this model will promote solar, wind biomass unit modular development is a development trend of green power.

\section{The Advantages of the Micro-Net Technology}

Distributed Generation is safe, reliable, energy saving and environmental protection, energy and power dispersion and concentration of flexible arrangement, the power flow in both directions, that is, with Plug When used in conjunction with the direct supply network has a good peaking performance can greatly improve the reliability of electricity supply. Supply network to crash or malfunction, accidental damage, but also to provide users with continuous power.

Distributed Generation for the grid in remote rural and pastoral areas is an effective energy supplement. The application of the Distributed Generation system will be a single centralized power supply system, an effective complement to, it can be more effective their energy use and development, but also to avoid the direct supply of economic losses due to failure blackout. Power Supply Bureau, under the normal power supply can be used as energy storage devices, uninterrupted power supply conditions, the user can select the distributed energy to provide safe and reliable electricity supply.

Distributed Generation in remote rural areas to solve the problem of electricity, improvement of rural life can be conditioned. Rural western China has abundant solar energy, wind energy, resources, especially biomass power generation, the western rural areas of the raw biomass (crop straw, firewood), the large number of widely distributed, the highest energy density in the renewable energy, so it is important to distributed energy base in China. In resource-rich western rural areas, priority should be given to the development of the use of biomass as the main power supply of the formation of micro-network. There by improving the living conditions in rural areas to improve the quality of life of the peasants, and rural electrification.

\section{Effect Analysis}

Distributed Generation is the only independent operation of the power supply system, its economy in some cases with direct supply comparable. Distributed Generation can also serve as a direct power supply reliable standby power, no lines, equipment investment; to some extent reduce line losses and unnecessary investment in power grid. Do not take up a lot of land, can also provide more energy saving and environmental protection. Distributed Generation can provide additional supply capacity, market selection and market ancillary services in remote pastoral areas without electricity problems for farmers to provide high-quality electricity, so that the farmers of the lower electricity costs, but also to avoid competition in the market power price rise, power generation companies, but also play a role in reducing the burden on farmers also produce good economic and social benefits of great significance to promote the efficient use of clean energy and rural electrification construction. 


\section{Conclusions}

In recent years, with the growing of China's western rural electricity consumption and electricity load, power system capacity serious lack of assurance industry, electricity is the mainstream of development in rural areas often "limited power" and "electricity shortage" tensions, which has become an important factor restricting China's rural economic development. Therefore, sustainable development and reduce environmental pollution to consider the Distributed Generation technology in rural areas will become an inevitable choice for China's. Current inputs are not enough; you also need the strong support of the policy to give more subsidies and investment policies, such as the rural Distributed Generation construction, which will make the Distributed Generation technology as soon as possible into the life of the majority of western farmers.

\section{REFERENCES}

[1] Z. Y. Liu, "Smart grid knowledge Reading," China Electric Power Press, Beijing, China, 2010, pp. 36-37.

[2] Z. Y. Liu, “Smart Grid Knowledge Quiz,” China Electric Power Press, Beijing, China, 2010, pp. 36-37.

[3] S. Q. Lu and Q. F. Li, "Research Survey and Prospects for the Application in China of Foreign Micro-grid," Huazhong Electrics, Vol. 22, No. 3, 2009, pp. 156-159.

[4] W. S. Huang and H. Yong, "Distributed Generation Distributed Generation Technology Research and Discussion,” Technology Eelectrics, Vol. 23, No. 9, 2009, pp. 14-18.

[5] Z. H. Zheng and Q. Ai, "Distributed Generation Research and Application Prospects in China," Technology Electrics, Vol. 32, No. 16, 2008, pp. 27-31.

[6] Q. S. Xiu, "Distributed Generation and Distributed Generation Technology,” Posts and Telecom Press, Beijing, China, 2010, pp. 65-68. 